\title{
Scaling of an Aviation Hydrogen Micromix Injector Design for Industrial GT Combustion Applications
}

\author{
Johannes Berger ${ }^{1,2}$ (D) \\ Received: 28 April 2021 / Revised: 18 July 2021 / Accepted: 26 July 2021 / Published online: 28 August 2021 \\ (C) The Author(s) 2021
}

\begin{abstract}
Decarbonising the energy grid through renewable energy requires a grid firming technology to harmonize supply and demand. Hydrogen-fired gas turbine power plants offer a closed loop by burning green hydrogen produced with excess power from renewable energy. Conventional dry low NOx (DLN) combustors have been optimized for strict emission limits. A higher flame temperature of hydrogen drives higher NOx emissions and faster flame speed alters the combustion behavior significantly. Micromix combustion offers potential for low NOx emissions and optimized conditions for hydrogen combustion. Many small channels, so-called airgates, accelerate the airflow followed by a jet-in-crossflow injection of hydrogen. This leads to short-diffusion flames following the principle of maximized mixing intensity and minimized mixing scales. This paper shows the challenges and the potential of an economical micromix application for an aero-derivative industrial gas turbine with a high-pressure ratio. A technology transfer based on the micromix combustion research in the ENABLEH2 project is carried out. The driving parameter for ground use adaption is an increased fuel orifice diameter from $0.3 \mathrm{~mm}$ to $1.0 \mathrm{~mm}$ to reduce cost and complexity. Increasing the fuel supply mass flow leads to larger flames and higher emissions. The impact was studied through RANS simulation and trends for key design parameters were shown. Increased velocity in the airgates leads to a higher pressure drop and reduced emissions through faster mixing. Altering the penetration depth shows potential for emission reduction without compromising on pressure loss. Two improved designs are found, and their performance is discussed.
\end{abstract}

Keywords Decarbonisation · Hydrogen Combustion · Stationary Gas Turbine $\cdot$ Industrial Gas Turbine $\cdot$ Micromix $\cdot$ NOx . Jet-in-Crossflow $\cdot$ Computational Fluid Dynamics $\cdot$ RANS $\cdot$ FGM

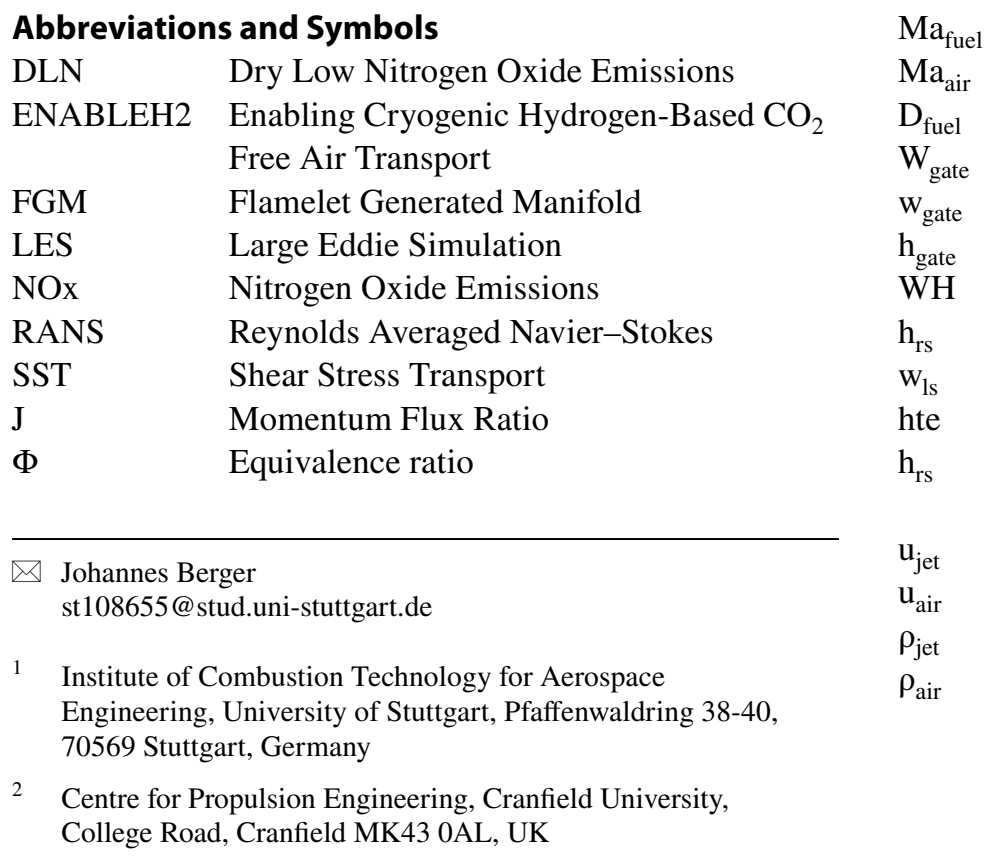

Mach number in the fuel orifice

Mach number in the airgate

Diameter of the fuel orifice

Airgate width

Non-dimensional airgate width

Non-dimensional airgate height

Width-to-height ratio of the airgate

Non-dimensional radial spacing

Non-dimensional lateral spacing

Non-dimensional Height trailing edge

Non-dimensional radial distance from pair

to pair

Velocity of the hydrogen jet

Velocity of the air in the airgate

Density of the jet

Density of the air in the airgate 


$\begin{array}{ll}\mathrm{o}_{\text {inj }} & \begin{array}{l}\text { Non-dimensional offset injection from } \\ \text { airgate outlet }\end{array} \\ \mathrm{o}_{\mathrm{te}} & \begin{array}{l}\text { Non-dimensional offset trailing edge from } \\ \text { injection }\end{array}\end{array}$

\section{Introduction}

The global average surface temperature in 2020 was $1.02{ }^{\circ} \mathrm{C}$ higher compared to the average temperature between 1950 and 1981 [1]. An uncontrolled increase in temperature led and presumably leads to devastating environmental and social catastrophes [2-4]. The global temperature change needs to be limited to well below $2{ }^{\circ} \mathrm{C}$ as named in the Paris Agreement [5] and this 'would require unprecedented transitions in all aspects of society', says the Intergovernmental Panel on Climate Change [6]. Decarbonising the energy systems and thus reducing the greenhouse effect by reducing carbon dioxide emissions is one measure to achieve the set goals. The potential use of hydrogen as an alternative energy carrier has recently been more widely recognized and is in the process of being explored.

Hydrogen can be applied to sectors in which electrification is not economically feasible and has the potential to firm the energy grid and harmonize the supply of renewable energy with demand through green hydrogen production [7]. This so-called power-to-gas process can form a decarbonised and firmed cycle of clean power utilizing a fuel cell or a stationary gas turbine for power production and potentially heat supply. A strategic positioning of the power plants can maximize the synergy effects of power supply and waste heat use as well as the blending with renewable energy sources [8].

Carbon-based fuels have been subject to research for decades. Auto-ignition times, flammability limits, mixing and quenching behavior have been and are intensively studied. An overview and detailed description can be found in Glassman et al. [9]. Specifically, gas turbines have been subject to research to lower emissions and increase cycle efficiency. In the past years, the development of combustors for dry and low nitrogen oxide (DLN) emissions has been the focus [10]. By lean premixing, the flame temperature has been lowered and thus NOx emissions have decreased.

However, due to significantly different combustion behavior, the current technologies and models are not easily adaptable for pure hydrogen combustion. Engine manufacturers of stationary gas turbines currently modify their state-of-the-art engines to a higher hydrogen content capability $[11,12]$. The first entirely hydrogen burning DLN industrial gas turbine with a power output of 1.1 MW has recently been put into use [13]. Aero gas turbines can be potentially modified for hydrogen combustion and enable flying without direct carbon emissions. The 'Enabling Cryogenic Hydrogen-Based $\mathrm{CO}_{2}$ Free Air Transport' (ENABLEH2) project coordinated by Cranfield University works to 'mature critical technologies for LH2-based propulsion' [14]. Part of this goal is to develop a novel micromix combustor for hydrogen combustion. The aim of this work is to investigate a technology transfer of hydrogen combustion in aero applications to stationary gas turbines. The research presented in this paper builds on the ongoing work and generated knowledge at Cranfield University [15-24] to develop a micromix hydrogen combustor for aero applications. In this paper, RANS CFD is used to model design adaptations and to assess their impact on flame structure, outlet conditions, and nitrogen oxide (NOx) emissions.

\section{Stationary Gas Turbine Combustion}

The requirements for gas turbine combustors are high combustion efficiency and low pressure loss, evenly distributed temperature on the outlet plane, and a minimum of emissions. Stationary gas turbines offer more freedom in design than their aero counterparts regarding size, weight and auxiliary systems [25]. On the other hand, a longer lifespan is desired as well as lower operating cost [10]. Combustors initially constructed for ground application as well as those derived from aero application were designed as diffusion flame combustors with uncontrolled NOx emissions. These diffusion flame combustors were later modified by adding demineralized water, steam or nitrogen as diluent and, because of the reduced flame temperature leading to reduced NOx emissions, met emission standards and could thereby increase power output. Using a diluent, however, limits the operability and drives direct operation cost of the engines and is thus not desired. Newer DLN combustors offer low levels of emissions of NOx through premixed, lean combustion at low flame temperatures. A variety of different DLN combustor designs for stationary gas turbines have been developed [26]. Multi-Fuel premixed DLN combustors offer superior operability but are challenging to control at all load levels regarding fuel and air levels, ambient conditions, and fuel composition. Introducing high hydrogen levels in the fuel alters the combustion behavior; flame speed, autoignition risk, thermo-acoustic risk, and flame temperature increase. Lower CO emissions and wider flammability limits are positive effects, but lower volumetric energy density requires adapted fuel supply controls and storage solutions [27]. Combustion of $100 \%$ hydrogen without diluent requires 'intensive R\&D activity to pave the way for such a technology' [28], since 'safe and reliable operation [for pure hydrogen combustion] is obtained in diffusion combustors only' [29].

Burning pure hydrogen and meeting emissions requirements as well as ensuring economical operability requires a new combustion technology. One of the promising 
technologies for burning hydrogen in gas turbines is micromix combustion. The leading principle is to maximize mixing intensity and minimize the mixing scale using many small high-velocity channels followed by a jet-in-crossflow injection of hydrogen resulting in a fast mixing, lean burning, short-diffusion flame. This is limited by compromising on the overall pressure loss [30] and manufacturability. The micromix principle is shown in Fig. 1 [18]: The inner and outer vortices stabilize the flame and ensure good mixing. The residence time and flame temperature are kept low to minimize the formation of thermal NOx but also flashback and auto-ignition risks are eliminated by not premixing air and fuel in the channels. Micromix has been subject to research at Aachen University of Applied Science working together with Kawasaki Heavy Industries [31]. NASA published a paper applying lean direct injection to develop a micromix-like 'low emission hydrogen combustor' [32]. A similar concept but with micro-premixing channels has been called 'Multi-Tube Mixer' by GE [33]. The micro-premixed 'multiple-injection burner' was researched by MHPS and Hitachi [34].

In the ENABLEH2 project, micromix combustion is being matured to TRL 3 for high-pressure ratio aviation application. This project explores feasibility of liquid hydrogen as an aircraft fuel and includes the fuel system as well. The micromix development focuses on Reynolds-averaged Navier-Stokes (RANS) and large eddie simulations (LES) adapted for micromix hydrogen combustion and their limitations [15-19], the design of the micromix geometry [20,21], and thermoacoustic modeling [22-24].

Stationary gas turbines are constrained by different boundary conditions, but a technology transfer still offers synergies. In a power plant application, gas turbine combustors face fewer challenges regarding altitude relight and critical safety measures. Weight and size limitations are less strict. Contrary to that, lifespan, development, production and direct operation cost are strongly restricted. Cranfield

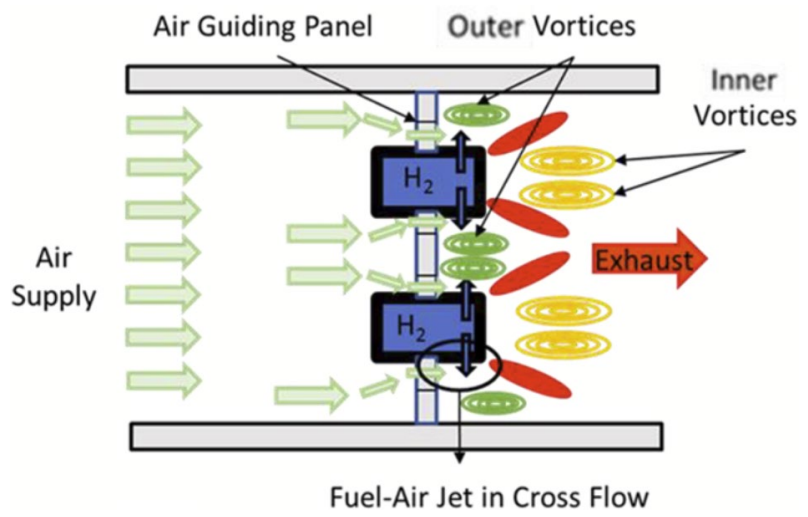

Fig. 1 Micromix combustion schematic from www.enableh2.eu
University's micromix system showed that a fuel orifice diameter of $0.3 \mathrm{~mm}$ is the best compromise of applicability and performance [20]. For this study, a diameter of $1.0 \mathrm{~mm}$ was selected as a design target to allow lower-quality fuel and compromise on cost and complexity, while attempting not to trade-off with increased NOx emissions. The change in fuel mass flow by increasing the fuel orifice diameter subsequently changes the air mass flow per gate, the airgate size, and the required number of airgates. A similar study was done by Haj Ayed et al. [35] at 1 bar, showing satisfactory results for a larger fuel orifice.

Less restrictive size and weight limitations as well as demand for multi-fuel capability and restrictive emission regulations led to the development of stand-alone industrial gas turbine combustor architectures [25]. This was due to the necessity of lean and staged combustion for higher residence times which reduce $\mathrm{CO}$ emissions but also produce low flame temperatures limiting NOx emissions. In general, the micromix system tends to have a larger cross section: the airstream is split into many airgates and the airgates need to be spaced out for flame separation leading to a higher blockage ratio than conventional combustors and thus to a larger face area for the airgate arrangement. On the other hand, due to the intense and fast mixing leading to short flames, the combustor length decreases. Following this, the architecture which suits micromix combustion best is the annular combustor with an increased face area. Redirecting the flow into can combustors as in a state-of-the-art stationary dry low natural gas combustor, which permit short shafts, long residence times and lean combustion, is not necessary.

The single shaft gas turbine is limited to lower pressure ratios and has a lower single-cycle efficiency. However, this is desirable for ground use because it leads to higher exhaust temperatures and supports a supercritical steam cycle, which leads to higher combined cycle efficiencies compared to a non-single shaft gas turbine. The combined cycle has a slower reaction time and is well suited for base loads and more predictable load changes. For adaptive grid firming, when quick reaction times are wanted, the aero-derivative two or three shaft stationary gas turbines stand out due to their high single-cycle efficiency and fast ramp-up time. Accordingly, for grid firming supporting renewable energies, the former industrial RB211, now SGT-A35, aero-derivative model was chosen as reference for this paper.

\section{Micromix Geometry Definition}

The cycle assessment based on data of the SGT-A35 from Siemens Energy [36] defined the necessary fuel and air mass flows. The total size limit for the combustor was defined by evaluating the engine cross section. Agarwal et al. [20] showed a rectangular airgate which has on the opposite side 
of the fuel injection an arch. This airgate shape was chosen for this paper, too. Sun et al. [17] varied the airgate shape and showed the beneficial effect of a pair arrangement for the flame structure. Placing the blunt side of the airgates towards each other as shown in Fig. 2 leads to a stronger recirculation between the gates. This helps to stabilize and form the flame as well as simplifies the design due to a single fuel tube for both airgates. The equivalence ratio $(\Phi)$ was set to 0.4 for lean and stable combustion and the Momentum Flux Ratio (J) was set to 5, which has shown good results in current simulations at Cranfield University. The Momentum Flux Ratio connects the density and velocity of fuel and airflow. This leads to a significant impact on the penetration depth and influences recirculation and flame merging. The Momentum Flux Ratio is defined as shown in (3.1):

$J=\frac{\rho_{\text {jet }} \cdot u_{\text {jet }}^{2}}{\rho_{\text {air }} \cdot u_{\text {air }}^{2}}$

The optimum fuel orifice diameter $\left(D_{\text {fuel }}\right)$ is $0.3 \mathrm{~mm}$ for hydrogen aero applications. However, in stationary gas turbines, a limitation of cost and the potential for blockage due to contaminants in pipeline delivered fuel makes a fuel orifice diameter of $1.0 \mathrm{~mm}$ desirable. The ratio of fuel-toair density is below $1 / 5$. Combined with a Momentum Flux Ratio of 5, this leads to a lower Mach number of air $\left(\mathrm{Ma}_{\mathrm{air}}\right)$ than fuel $\left(\mathrm{Ma}_{\text {fuel }}\right) . \mathrm{Ma}_{\text {fuel }}$ was limited to 0.3 to avoid compressibility effects and high-pressure losses. The fuel mass flow per gate was obtained through the assumption of $D_{\text {fuel }}$ and $\mathrm{Ma}_{\text {air }}$ With the set equivalence ratio, this leads to the airflow per gate. Keeping the Width-to-Height ratio (WH) at 1 as in [20] yields the airgate size $\left(\mathrm{w}_{\text {gate }}\right.$ and $\left.\mathrm{h}_{\text {gate }}\right)$. The total number of airgates was found by dividing the total fuel flow by the single airgate fuel flow. The key airgate design parameters are shown in Fig. 2. With the available total design space for the injector plate, limiting the trailing edge height $\left(h_{t e}\right)$ to a set value to accommodate the fuel tube and aiming for $6 \mathrm{~mm}$ in radial distance $\left(\mathrm{h}_{\mathrm{rs}}\right)$ from pair to pair to avoid radial merging in between airgate pairs, the number of rows and subsequently the radial and lateral spacing $\left(\mathrm{h}_{\mathrm{rs}}, \mathrm{w}_{\mathrm{ls}}\right)$ of an airgate were found. A reference baseline design for a pair of airgates with a fuel orifice diameter of $0.3 \mathrm{~mm}$ is shown on the left side of Fig. 3. Following the same design routine for a fuel orifice of $1.0 \mathrm{~mm}$ leads to the baseline design on the right in Fig. 3.

\section{Simulation Setup}

Combustion simulation is challenging because it necessitates resolving a broad range of three-dimensional and timedependant scales of the combustion process and flow field, which influence each other. The geometries were modeled in STAR-CCM + using RANS with k- $\omega$ Menter shear stress transport (SST), the reaction mechanism from Naik et al. $[37,38]$ and the Zeldovich combustion model. The models are set up to be three-dimensional, ideal gas with segregated flow and fluid enthalpy, and an all y + wall treatment. The chosen RANS approach limits computational power necessary but produces only time-averaged solutions. The turbulent mixing of micromix combustion is expected to produce a dynamic flow field and local hot spots cannot be captured by RANS. The chosen k- $\omega$ SST model combines the positive effects of the k- $\omega$ and k- $\varepsilon$ models: good boundary layer and free flow resolution. The mechanism from Naik is applied via FGM: a reduced number of parameters are
Fig. 2 Airgate Design Parameters
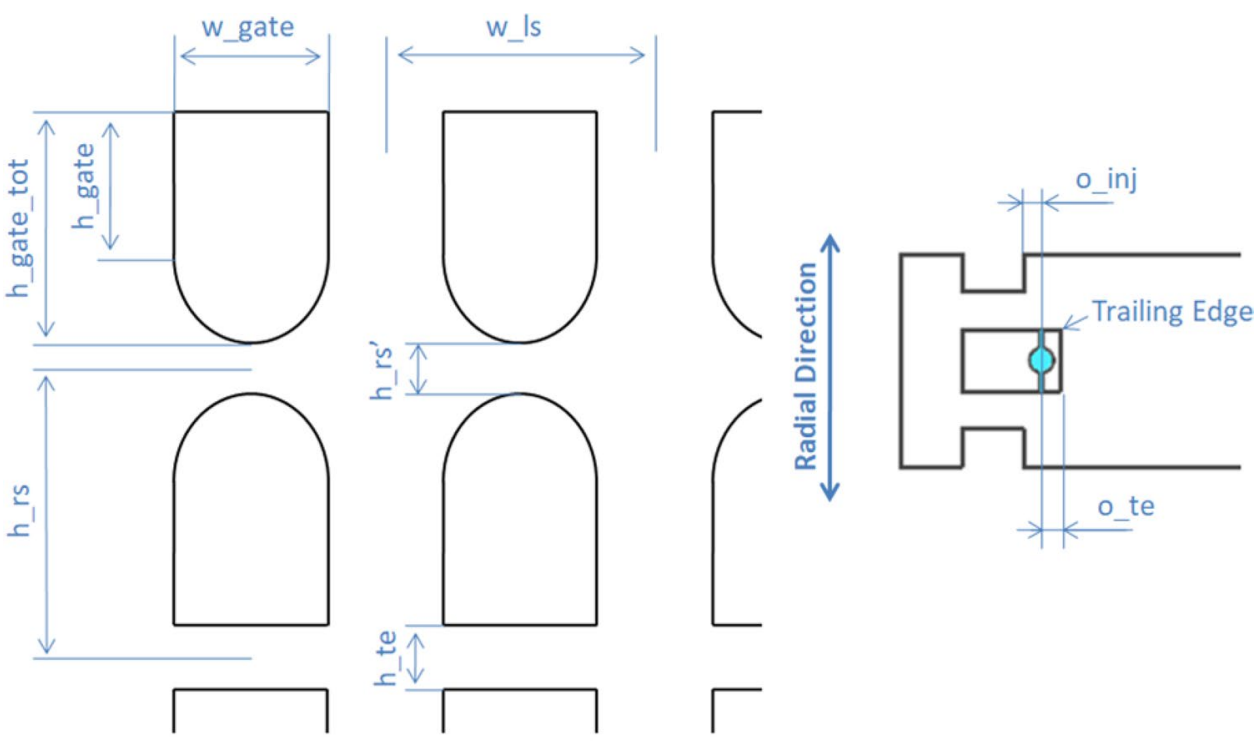

Lateral Direction 
Fig. 3 Baseline Micromix Combustor (left) and scaled version (right) to accommodate a fuel orifice of $1.0 \mathrm{~mm}$. Crosswise section through airgates scaled to $2: 1$

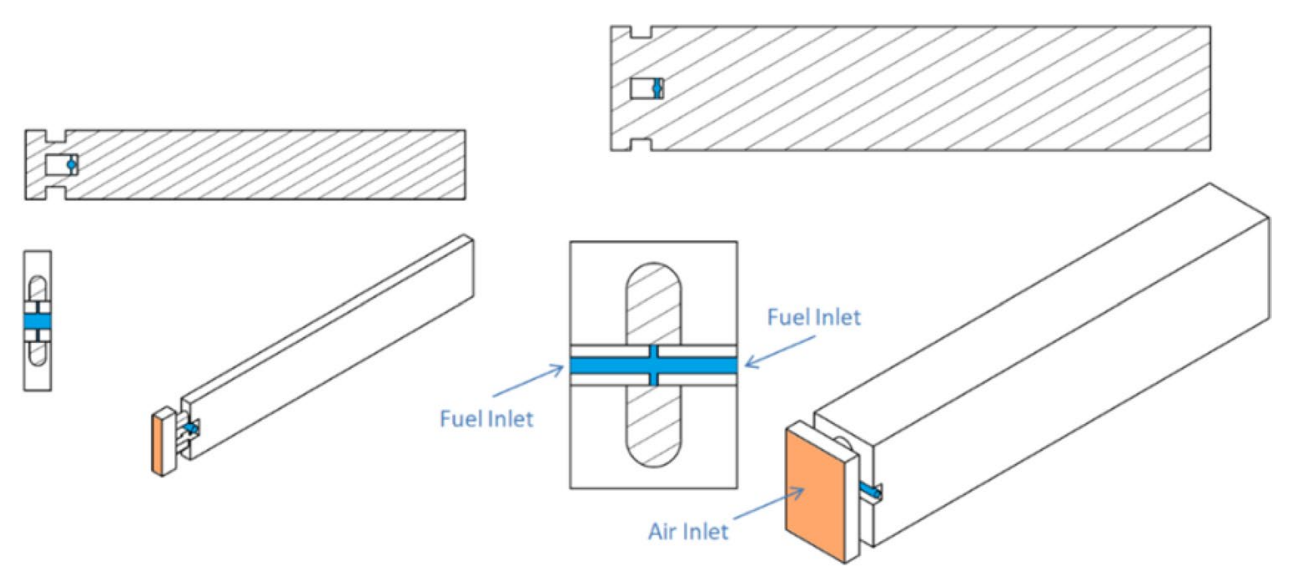

solved during the simulation and through these, the combustion is modeled using a previously computed lookup table. This approach reduces the stiffness of the model and leads to a faster convergence.

The baseline designs are shown in Fig. 3. In an annular combustor, the injectors will be arranged side by side in the lateral direction to form a ring around the engine core and stacked row on row in radial direction. A total of three inlets are defined: the air inlet upstream of the pair of micromix gates and two hydrogen inlets into the fuel supply tube. Symmetry is used for the radial surfaces and interface boundary conditions connect the lateral boundaries. The domains are discretized by two to three million cells. The polyhedral mesh with prismatic boundary layer ensures good resolution of the eddies and boundary layer while optimizing the cell count. Within the gates, the orifice and the flame area, the mesh has been refined. The increased mesh base size is found to not affect the solution. The overall mesh independence using an intermediate design with a fuel orifice diameter of $0.6 \mathrm{~mm}$ is shown in Fig. 4: results obtained with a mesh base size of $0.6 \mathrm{~mm}$ and $0.9 \mathrm{~mm}$ are within the expected limited numerical deviation.

Assessing a single cycle of the SGT-A35 based on data available in Gas Turbine World [39] in ambient conditions yielded a combustor entry temperature of $800 \mathrm{~K}$ and
22.6 bar. An isentropic efficiency of 0.82 for the compressor and 0.8 for the turbine was assumed to match the given outlet conditions. The fuel temperature was set to $300 \mathrm{~K}$ to mirror non-cryogenic storage on ground or pipeline outlet conditions.

The combustion is modeled using the flamelet-generated manifold (FGM) approach. The computational cost in this approach is limited by resolving the fast chemical time scales separated from the flow based on a look-up table for the chemistry parameters and, by doing so, making the model less stiff. The species and temperatures are parametrized, and the transport equations are solved for the parametrizing variables. Based on the table and the differential equations for the parametrizing variables, the chemical kinetics are statistically embedded into the flow field. The FGM model can predict non-equilibrium effects which 'are not negligible in this context. Hence, the FGM model was deemed most suitable to capture the turbulence-chemistry interaction inside the micromix combustion chamber' [15] and performed best in the investigation of Funke et al. [40]. However, the FGM model is not able to capture all non-equilibrium effects, such as the slow chemistry of NOx formation, and 'only trends can be correctly predicted' [16]. Zghal et al. [19] found that the RANS FGM model under-predicts the flame temperature by averaging, and thus the NOx emissions, compared
Fig. 4 Comparison of different mesh base sizes for identical domains

\section{Mean Temperature Rise Downstream}

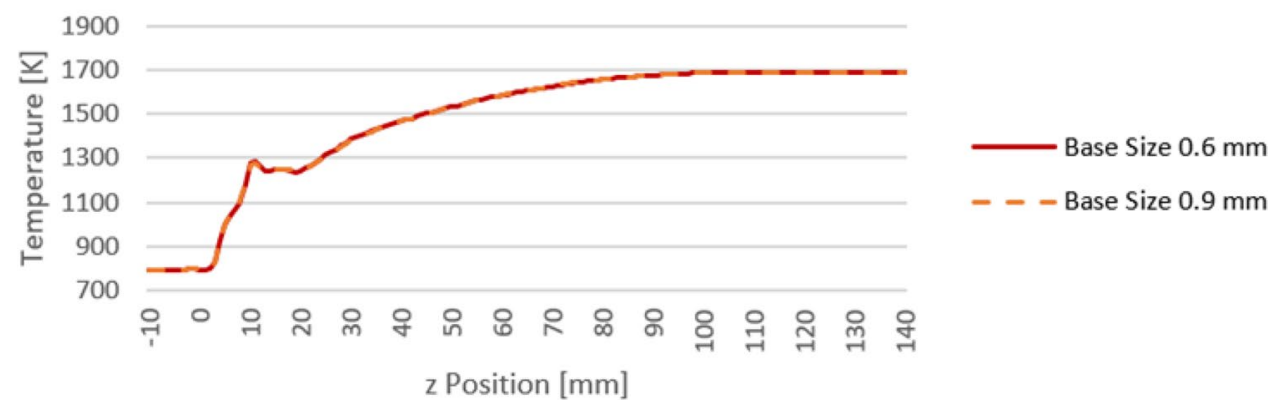


to LES simulations. This also highlights the limitation of absolute NOx values, but the error can be held 'within reasonable tolerances' [19] and needs experimental data for proper validation. The turbulent Schmidt number was set at 0.2 following López-Juárez et al. [18] to compromise on prediction of NOx emissions and flame length. The chosen setup trades off complexity and computational cost which leads to an error in prediction in NOx values but allows cross-model comparison and trend prediction. Experimental data are needed to validate this simulation and to interpret the absolute values correctly.

With this setup, the variation of design parameters was assessed regarding the flame structure and anchoring, the thermal NOx formation, the temperature profiles, and the distribution of hydroxyl $(\mathrm{OH})$ radicals. The enlarged $1.0 \mathrm{~mm}$ fuel orifice results in larger flames and subsequently in longer residence times and higher NOx emissions. The design parameters have been varied to understand the possibility to mitigate negative impacts and to find an improved design for stationary gas turbine application.

\section{Micromix Design Adaption}

The original design introduces turbulence to form rapidly micromixed diffusion flames leading to low-peak temperatures and short residence times. The recirculation zones shape and anchor the flame but should not generate hotspots to ensure low thermal NOx formation. Merging of the flames can lead to larger flames with higher residence times and should be suppressed by the recirculation zones. The parameters for both baseline designs are given in Table 1. They have been kept mostly constant while scaling to ensure similar behavior and comparability. Changing the fuel orifice diameter leads to larger airgates and a lower total number of airgates. The scaling can increase flame length, thus the CFD domain length was increased. The base size of the mesh was increased to keep the cell count constant and limiting computational cost. The non-dimensional parameters are based on the respective value of Baseline $0.3 \mathrm{~mm}$. The equation below (5.1) was adjusted and applied for each dimensionless variable:

$w_{\text {gate }}=\frac{W_{\text {gate }}}{W_{\text {gate, Baseline } 0.3 \mathrm{~mm}}}$

MOMENTUM FLUX RATIO (Imposed initial value: $J=5$ ) The Momentum Flux Ratio (J) connects the product of density and velocity of the jet and the airstream. Altering $\mathrm{J}$ leads to a change in the penetration depth of fuel and influences the flame position and merging tendency. Changing $\mathrm{J}$ leads to a higher or lower $\mathrm{Ma}_{\text {air }}$ affecting the airgate size, since $\mathrm{Ma}_{\text {fuel }}$ is kept continuously at 0.3 and no density changes occur.

MACH NUMBER (Imposed initial limit: $M a_{f u e l}=0.3$ ) $\mathrm{Ma}_{\text {fuel }}$ at a Momentum Flux Ratio of 5 is higher than $\mathrm{Ma}_{\text {air }}$ This leads to limiting $\mathrm{Ma}_{\text {fuel }}$ to 0.3 rather than limiting $\mathrm{Ma}_{\text {air }}$ An increased Mach number of fuel and by that an increased mass flow, while maintaining the equivalence ratio of 0.4 , leads to an increased $\mathrm{Ma}_{\text {air }}$ and air mass flow through the airgate. For example, the increased velocity affects the turbulent eddies and can wash the flame further downstream, but might also lead to critical effects such as compressibility.

WIDTH-TO-HEIGHT RATIO (Initial value: $W H=1$ [18]) The airgate cross section consists of a rectangular base and a half-circle on top. The ratio between airgate width and height (WH) without the top half-circle is set to 1 . Changing the ratio affects the penetration depth, the flame shape and its lateral and radial dimension as well as offers a wider or narrower lateral recirculation. It is defined as shown in (5.2):

$W H=\frac{w_{\text {gate }}}{h_{\text {gate }}}$
Table 1 Baseline Design Parameters

\begin{tabular}{llll}
\hline Variable & Abbreviation & Baseline $0.3 \mathrm{~mm}$ & Baseline $1.0 \mathrm{~mm}$ \\
\hline Diameter fuel orifice & $\mathrm{D}_{\text {fuel }}$ & $0.3 \mathrm{~mm}$ & $1.0 \mathrm{~mm}$ \\
Non-dimensional airgate width and height & $\mathrm{w}_{\text {gate }}, \mathrm{h}_{\text {gate }}$ & 1 & 3.33 \\
Number of gates, approx. & & 13,800 & 1200 \\
Airgate width-to-height ratio & $\mathrm{WH}$ & 1 & 1 \\
Domain length & - & $100 \mathrm{~mm}$ & $140 \mathrm{~mm}$ \\
Momentum flux ratio & $\mathrm{J}$ & 5 & 5 \\
Mach number fuel & $\mathrm{Ma}_{\text {fuel }}$ & 0.3 & 0.3 \\
Non-dimensional offset airgate outlet to injection & $\mathrm{o}_{\text {inj }}$ & 1 & 1 \\
Non-dimensional offset injection to trailing edge & $\mathrm{o}_{\text {te }}$ & 1 & 1 \\
Airgate thickness & - & $5 \mathrm{~mm}$ & $5 \mathrm{~mm}$ \\
Cell count in million, approx. & - & 2.3 & 2.3 \\
Mesh base size & - & $0.4 \mathrm{~mm}$ & $0.9 \mathrm{~mm}$ \\
\hline
\end{tabular}


INJECTION OFFSET AND OFFSET TO TRAILING EDGE (Initial value: $o_{i n j}=o_{t e}=1$ [18]) The center of the fuel injection outside the airgate and close to the outlet. The trailing edge is further downstream to accommodate the fuel tube. Both parameters are the same for both, $0.3 \mathrm{~mm}$ and $1.0 \mathrm{~mm}$ Baselines, and not scaled to limit the number of changed parameters. Both affect mixing and merging of the flames and influence the heat transfer to the trailing edge.

TRAILING EDGE HEIGHT (Imposed initial value: $\left.h_{t e}=1\right)$ The trailing edge height $\left(\mathrm{h}_{\mathrm{te}}\right)$ is an important parameter: it defines how the flames of each airgate pair affect each other through recirculation and influences the overall injector plate size, but also needs to accommodate space for the fuel supply.

ROUNDING The baseline designs are set up to have sharp edges. This can be challenging for manufacturing and increases the boundary layer size within the channel. Rounding the airgate inlet significantly reduces the boundary layer in the airgate and decreases the pressure drop. Rounding the edges of the trailing edge works as a diffuser and can help pushing the flame anchoring point to a more suitable position.

AIRGATE THICKNESS (Imposed initial thick$n e s s=5 \mathrm{~mm}$ ) Lengthening the channels should affect the flow similarly to a rounded airgate inlet and show a more developed flow in the airgate.

\section{Results}

The starting point to understand the effect of scaling the fuel orifice in the presented results are the 'Baseline' configurations with a $\mathrm{D}_{\text {fuel }}$ of $0.3 \mathrm{~mm}$ and $1.0 \mathrm{~mm}$ shown in Fig. 3. The Baseline $0.3 \mathrm{~mm}$ model shows NOx emissions of $99 \mathrm{ppm}$ dry and corrected to $15 \%$ oxygen. As discussed, the absolute value is not trustworthy, so all other values are given normalized by the predicted NOx emissions of $456 \mathrm{ppm}$ of the Baseline $1.0 \mathrm{~mm}$ model to understand the trends. The Baseline $1.0 \mathrm{~mm}$ performance regarding NOx was worse than the Baseline $0.3 \mathrm{~mm}$. In this paper, the potential to mitigate this impact by adapting the key design parameters is explored. This was done by changing one design parameter after the other and comparing the results to the Baseline $1.0 \mathrm{~mm}$. Two designs were chosen based on this variation. The first design is improved to imitate the flame structure of the Baseline $0.3 \mathrm{~mm}$ model, the second model to perform well under an emissions viewpoint.

BASELINE CONFIGURATIONS The Baseline models show a significantly different combustion behavior. In the top row of Fig. 5, the Baseline $0.3 \mathrm{~mm}$ is shown on the left and the Baseline $1.0 \mathrm{~mm}$ is shown on the right. The Baseline $0.3 \mathrm{~mm}$ design is characterized by two separated flames each with a hot core in which the NOx formation rate is high.
The residence time in those regions is rather short due to the short flames. Contrary to that, in the Baseline $1.0 \mathrm{~mm}$, the hot zone recirculates to the trailing edge and forms one large flame region merging both airgate streams together. NOx forms in the stagnating area at the trailing edge and high concentrations of hydroxyl radicals lead to high NOx formation in the main combustion area. The large area of hydrogen in a flammable range suggests that the unburnt fuel is sucked early into the recirculation zone and that the residence time in the hot zone is long. The first entry in the legends of Figs. 6, 7 refers to the Baseline configurations. The NOx emissions trend including a Baseline $0.6 \mathrm{~mm}$ case is shown in Fig. 6. The pressure loss shown in Fig. 7 is increasing slightly with a larger airgate while maintaining the same blockage ratio.

PARAMETER VARIATION The key parameters were isolated and gradually changed to obtain trends. The impact on NOx emissions and pressure drop is shown in Figs. 6, 7, 8, 9. Figures 5, 6 show the trendlines of parameter varied in steps and Figs. 8, 9 show the impact of singular parameters. $\mathrm{Ma}_{\text {fuel }}$ and $\mathrm{J}$ both impact the air velocity. Changing $\mathrm{Ma}_{\text {fuel }}$ influences the necessary airflow to keep the equivalence ratio constant and reducing $\mathrm{J}$ leads to an increase of $\mathrm{Ma}_{\text {air }}$ independently of $\mathrm{Ma}_{\text {fuel }}$. WH affects the penetration depth into the main airflow. A wider gate circulates more air around and later under the fuel jet. This does not change $\mathrm{J}$ and thus not change the airspeed and the pressure drop. Increasing the distance from airgate exit to fuel injection $\left(o_{\text {inj }}\right)$ has a similar effect as changing WH. The airflow flattens and widens leaving the airgate. It is flowing around the fuel jet and this leads to a higher penetration depth of fuel. By increasing the distance between fuel injection and trailing edge $\left(\mathrm{o}_{\mathrm{te}}\right)$, the flame gradually attaches stronger to the trailing edge. Increasing $h_{\text {te }}$ from 1 to 1.36 , which then is identical to the airgate height, leads to an increased recirculation and no change in the pressure drop. The rounding of the airgate inlet reduces the boundary layer and reduces the pressure drop to almost $50 \%$ of Baseline $1.0 \mathrm{~mm}$. Rounding the trailing edge affects the flow field and reduces the temperature directly at the trailing edge. Increasing the wall thickness from 5 to $10 \mathrm{~mm}$ allows the flow to develop in the airgate and acts similar to the rounding of the airgate inlet or an increased Momentum Flux Ratio, but not as strong.

Mach number $\left(\mathrm{Ma}_{\text {fuel }}\right)=[0.2,0.3,0.4,0.5,0.6]$ and Momentum Flux Ratio $(J)=[1,3,5,7,9]$ in Figs. 6, 7: The trends show that increasing the airgate velocity, through either parameter, leads to a reduction of NOx emissions but increase in pressure drop. The higher velocity stretches the flame region downstream, but also narrows the hot zone resulting in a lower residence time. The zone containing high concentrations of $\mathrm{OH}$ radicals can be greatly reduced. The designs with decreasing air velocity show a longer residence time and lower mixing of the hot gases downstream 
Fig. 5 Plots of the Mean values of Temperature, H2 Mass Fraction, $\mathrm{OH}$ Mass Fraction and NOx Formation Rate for the Baseline $0.3 \mathrm{~mm}$, the Baseline $1.0 \mathrm{~mm}$ design, the design for an Improved Flame Shape $\left(\mathrm{D}_{\text {fuel }}=1.0 \mathrm{~mm}\right)$ and the design for Improved Emissions $\left(\mathrm{D}_{\text {fuel }}=1.0 \mathrm{~mm}\right)$ from top left to bottom right. The designs are shown to the same scale: Domain height and width vary due to changes in the height and width of the airgate and the height of the trailing edge

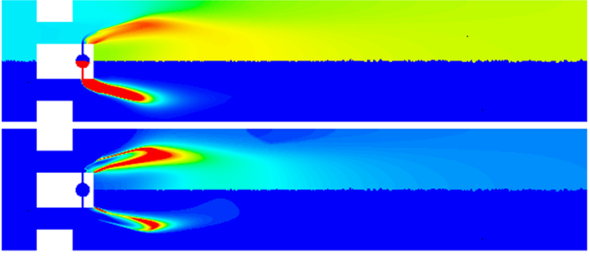

Baseline $0.3 \mathrm{~mm}$

Improved Flame Shape

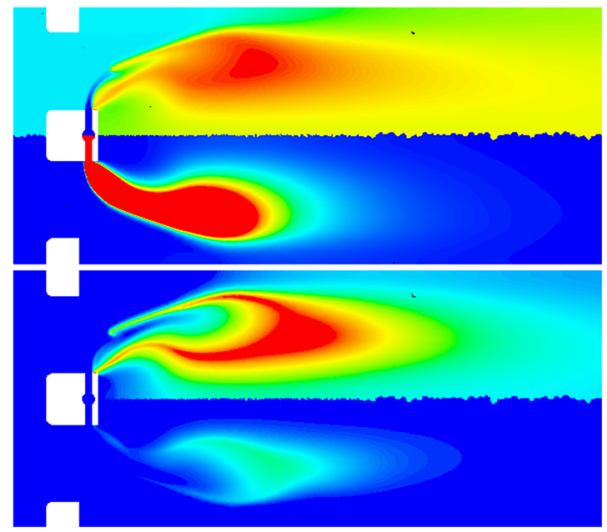

Mean of Temperature $(K)$ 1500.00

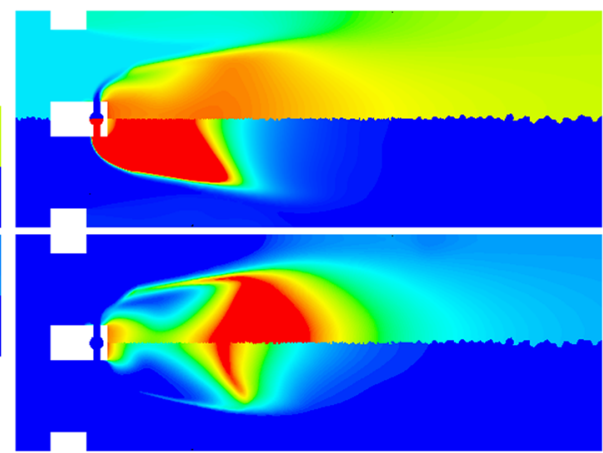

Baseline $1.0 \mathrm{~mm}$

Improved Emissions

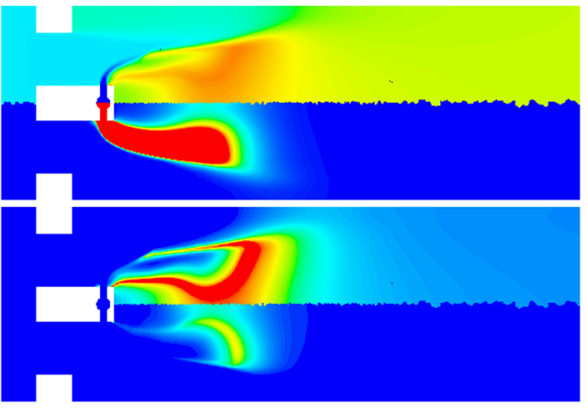

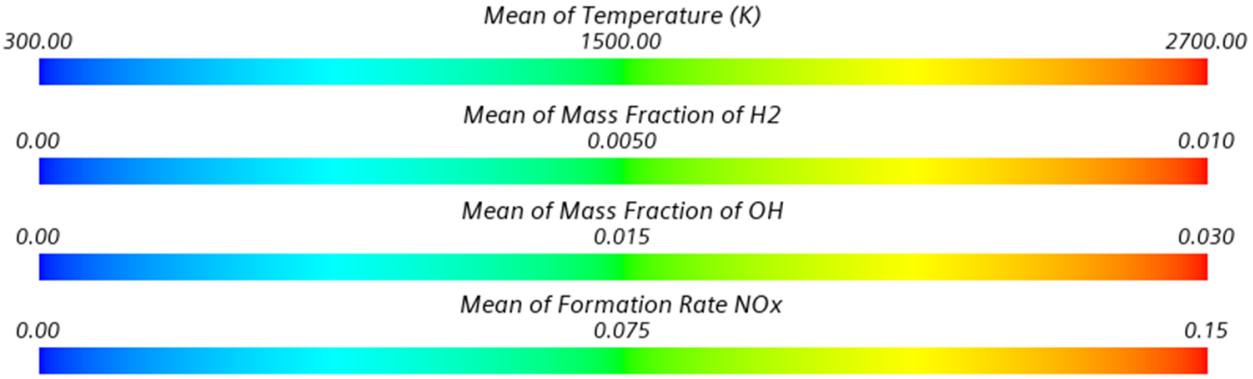

combined with a prolonged formation of NOx further downstream. For $J=7$, the trend shows a surprising behavior. In this case, a smaller recirculation zone forms right after the trailing edge which is not as hot as in the other designs. This lowers the residence time in the following hot zone. The change in pressure drop for the variation of both parameters follows the same trend and is not negligible. The best design from an emissions standpoint (up to 65\%) shows the highest pressure drop (10\%) and vice versa.

Width-to-Height Ratio $(\mathrm{WH})=[0.8,1,1.2,1.4,1.6,2.0$, 2.4] in Figs. 6, 7: Increasing WH and thus increasing penetration depth help to separate the NOx formation region from the trailing edge and reducing NOx for the cases up to a ratio of 1.6. At 2.0 and 2.4, the heat release region merges with the top and bottom interfaces leading to a stagnating trend, but a strong and short recirculation zone with better NOx emissions than Baseline $1.0 \mathrm{~mm}$. A negative impact on the emissions is shown by a higher airgate with a ratio of 0.8 .
The penetration depth decreases and the mixing downstream is not as efficient anymore leading to a stretched region of high NOx formation. None of the designs change the pressure drop significantly.

Offset from airgate to fuel injection $\left(\mathrm{o}_{\text {inj }}\right)=[1,2,3,4$, 5] in Figs. 6, 7: The trend to lower emissions is due to the altered recirculation zone. The recirculation does not transport hot gas or hydroxyl back to the trailing edge. At $o_{i n j}=5$, the trend is turned around because the recirculation zone splits up downstream and stagnates leading to a larger hot gas zone with higher residence times. This parameter variation does not affect the pressure drop majorly.

Offset from fuel injection to trailing edge $\left(o_{t e}\right)=[1,2,3$, 4, 5] in Figs. 6, 7: The effect of a longer offset is inconsistent, but on average, it lowers the emissions. The impact on the emissions in the first step to $o_{t e}=2$ is minor. The flame gets pushed downstream and the recirculation zone slightly stretched. The flame and NOx formation attach strongly to 


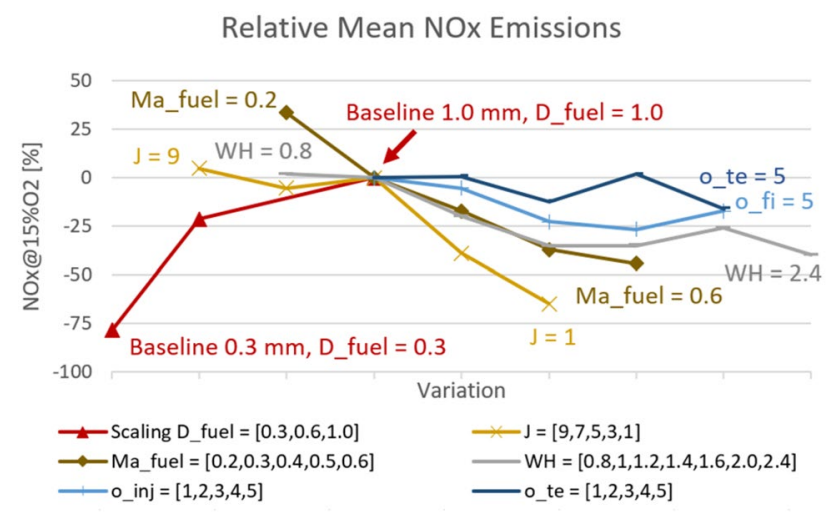

Fig. 6 Relative NOx emission trends of selected parameters

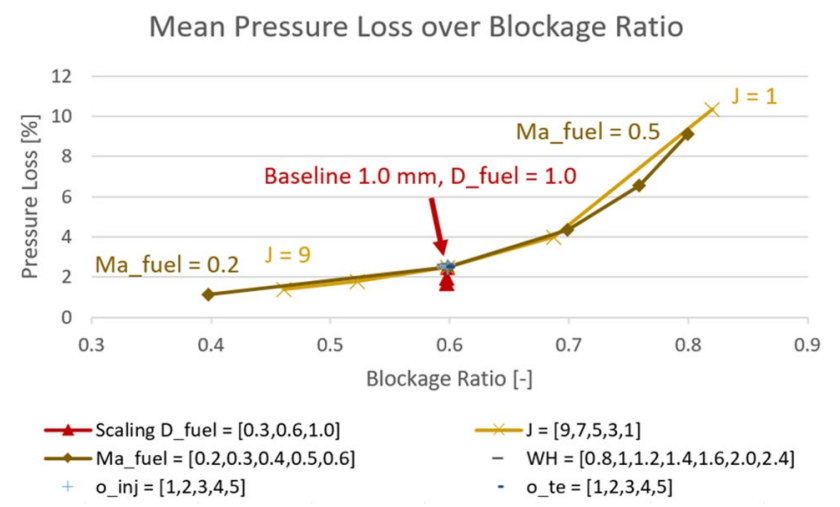

Fig. 7 Pressure loss over blockage ratio trends of selected parameters

the trailing edge for the cases with $\mathrm{o}_{\mathrm{te}}=3$ and $\mathrm{o}_{\mathrm{te}}=5$. Both show an early formation of NOx in the recirculation to the trailing edge, but also a very high temperature close to the trailing edge. This effect gets disrupted at $\mathrm{o}_{\mathrm{te}}=4$ by hot gas in a stagnating zone increasing NOx production additionally to the NOx formation close to the trailing edge. The pressure loss for these designs is almost identical to the Baseline $1.0 \mathrm{~mm}$ design.

Trailing edge height $\left(\mathrm{h}_{\mathrm{te}}\right)=1.36$ in Figs. 8, 9: The stronger recirculation due to the increased trailing edge height increases the residence time and the emissions rise. Reducing the trailing edge height is limited by the necessity for a fuel tube in between the gates and the structural and thermal integrity of the trailing edge.

Rounding the airgate inlet in Figs. 8, 9: The rounded inlet can be interpreted similarly to increasing $\mathrm{J}$. The thinner boundary layer reduces peak velocity and the velocity profile at the airgate outlet. Accordingly, the flow field shows less turbulences and forms a larger hot gas recirculation zone. This suggests that the rounding works similar to increasing J significantly. The boundary layer narrows the flow

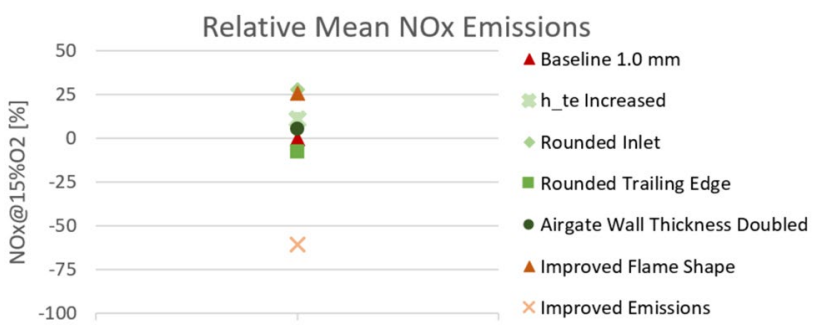

Fig. 8 Relative Mean NOx emissions change by singular parameters

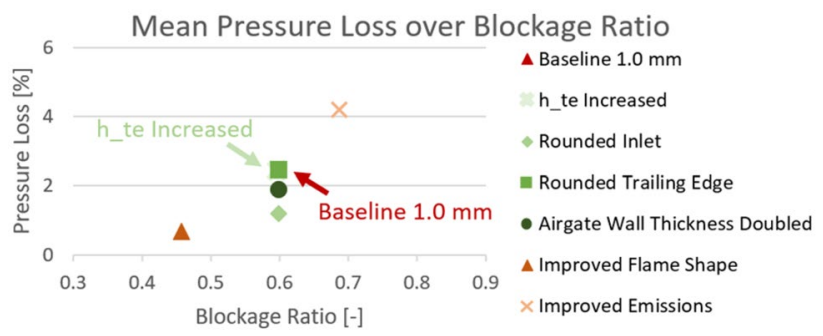

Fig. 9 Pressure loss over blockage ratio change by singular parameters

cross-sectional area and the local Momentum Flux Ratio for the designs with sharp inlets is presumably lower than the calculated value.

Rounding the trailing edge in Figs. 8, 9: Rounding the trailing edge leads to the reduction of NOx formation right after the trailing edge and thus slightly better emissions. The hot gas is less attached while the pressure loss stays constant. The following recirculation zone is not visibly affected.

Doubling the airgate wall thickness in Figs. 8, 9: The larger airgate wall thickness shows increased NOx emissions due to a stronger recirculation to the trailing edge similar to increasing J. The pressure drop is not affected. The thickness is limited due to structural integrity and the necessity to integrate the fuel tube in the injector plate.

IMPROVED FLAME SHAPE (Figs. 8, 9) The flame shape of Baseline $0.3 \mathrm{~mm}$ is significantly different to Baseline $1.0 \mathrm{~mm}$ : The flames are not separated anymore and the formation of NOx isn't limited to two distinct zones. By combining variations in three of the previous parameters, a similar flame structure and $\mathrm{D}_{\text {fuel }}=1.0 \mathrm{~mm}$ was achieved. This is shown in the bottom left of Fig. 5. The Momentum Flux Ratio is set to 9, the airgate inlet is rounded and the trailing edge height increased to the gate height. All of these parameters alone increased the NOx emissions, yet the combination did not just accumulate the negative impact. In fact, it shows better results than the rounded airgate inlet design alone. The negative impact was reduced by the effect of the separated flames. Nevertheless, the emissions are 25\% higher compared to Baseline $1.0 \mathrm{~mm}$. In Figs. 10, 11 the 


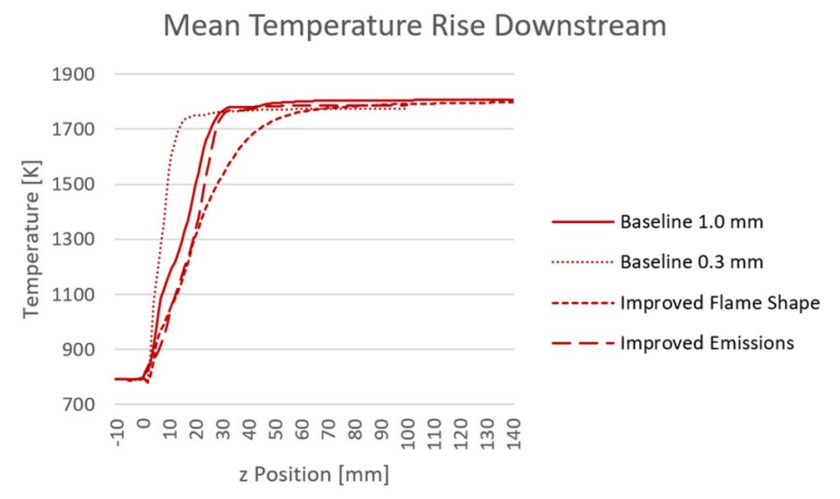

Fig. 10 Mean temperature distribution averaged on cross sections of Baseline $1.0 \mathrm{~mm}$, Baseline $0.3 \mathrm{~mm}$, the design for an Improved Flame Shape and the design for Improved Emissions

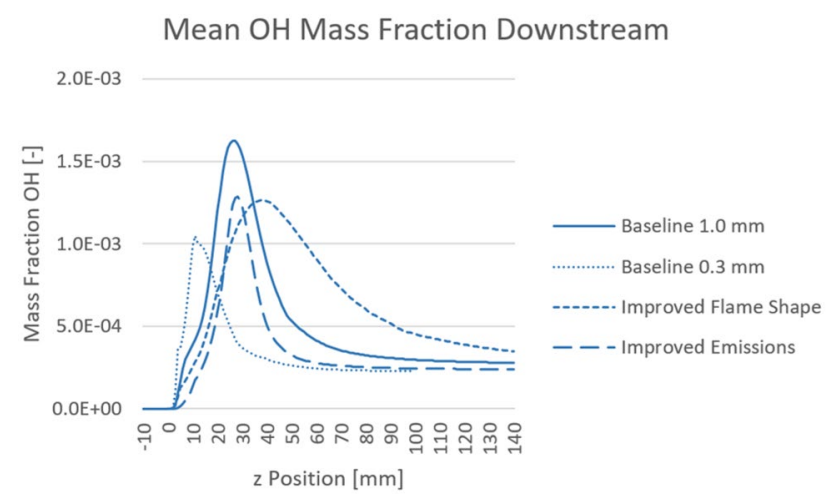

Fig. 11 Mean hydroxyl mass fraction rise on cross sections of Baseline $1.0 \mathrm{~mm}$, Baseline $0.3 \mathrm{~mm}$, the design for an Improved Flame Shape and the design for Improved Emissions

temperature and $\mathrm{OH}$ mass fraction is shown. The reason for the worse emissions is due to the reduced temperature gradient and high hydroxyl concentration downstream because of the longer flames. The hot gas zone is accordingly long, the residence time is high and the peak temperature above the peak temperature of the other designs. However, this design has the lowest pressure drop of all shown designs.

IMPROVED EMISSIONS (Figs. 8, 9) A combination of variation in three parameters was also used to find a design with low emissions and a fuel orifice of $1.0 \mathrm{~mm}$. The greatest single influence on emissions is the air velocity. The change of Momentum Flux Ratio does not increase the fuel velocity and was chosen to avoid negative effects due to too high fuel stream velocities. A compromise between pressure drop and emissions performance was made and $\mathrm{J}$ was set to 3 , which previously led to a pressure drop of $4 \%$. A design with $\mathrm{J}$ increased to 7 to reduce emissions is possible, but the effect is not as significant as a lowered Momentum Flux Ratio. WH is set to 2 . This might seem exaggerated from the given data, but the change in Momentum Flux Ratio affects the penetration inversed to the increase in $\mathrm{WH}$. The offset from airgate exit to fuel injection was set to 3 to profit from the positive effect on the flame structure and emissions. The results are shown in the bottom right of Fig. 5. The hot zone is smaller and the $\mathrm{H} 2$ and $\mathrm{OH}$ plot even show an unexpected tendency of flame separation. The NOx formation rate decreased in value and the area got smaller. Overall, the emissions were reduced by more than $50 \%$. Only even higher $\mathbf{J}$ and thus a higher pressure drop as well as the Baseline $0.3 \mathrm{~mm}$ showed better results. The pressure drop is as expected increased to around $4 \%$. The temperature gradient in Fig. 10 is higher, especially considering the trailing edge ends further downstream. The $\mathrm{OH}$ emissions plotted in Fig. 11 underline the positive effects by showing overall reduced $\mathrm{OH}$ concentrations.

\section{Limitation}

The presented work is exploring micromix combustion for a high-pressure ratio stationary gas turbine at a base load of more than $30 \mathrm{MW}$. The inlet conditions are $800 \mathrm{~K}$ and 22.6 bar. The high pressure and temperature as well as energy density are expected to lead to higher NOx emissions underlining the challenges of hydrogen combustion. There are no experimental data for the micromix design at these conditions to compare to and thus, in combination with the restrictions of RANS simulations, the significance of absolute values is limited. The simulation itself does not capture time-dependant effects and a further analysis and verification using LES is advisable. Nevertheless, this study focuses on trends which can be predicted by RANS simulations.

Not only is the simulation limited by the specific numerical setup, but more so the simulation of hydrogen in general is challenging due to the altered combustion behavior [41]. Deeply studied and validated combustion mechanism are available for hydrocarbon fuels, but the experimental study regarding flame speed and ignition time delay of Kéromnès et al. showed over a wide pressure and equivalence ratio range, how 'reactivity of the syngas mixtures was found to be governed by hydrogen chemistry for $\mathrm{CO}$ concentrations lower than $50 \%$ in the fuel mixture' [42]. Accordingly, the reaction mechanisms need to be adapted [43]. The mechanism by Naik et al. in combination with the FGM applied in this paper is recommended by Zghal et al. [19], who studied it using RANS and LES simulations adapting complex chemistry, the thickened flame method and the flameletgenerated manifold approach. Furthermore, the assumption of Schmidt, Lewis and Prandtl number equal to 1 for hydrocarbon fuels needs to be altered according to [18] to properly represent hydrogen combustion within the presented modeling approach. The proposed values are studied comparing 
LES and RANS simulations and applied in the presented study. One of the affected aspects is the increased diffusivity of hydrogen, which needs to be properly replicated, but applied micromix combustion lacks data at high pressure to confirm or revoke the model assumptions. Comparable experimental data from Cranfield University's test rig fitted for hydrogen micromix combustion are expected within this year.

The experimental data available at atmospheric conditions from Haj Ajed et al. show for micromix combustion NOx emissions slightly above $2 \mathrm{ppm}$ (measured) and NO emission slightly below $2 \mathrm{ppm}$ (calculated) with a hydrogen orifice of $1.0 \mathrm{~mm}$ and an equivalence ratio of 0.4 [35]. In the numerical design exploration, the authors were able to reduce the NO emissions to as little as $0.28 \mathrm{ppm}$ at 1 bar and $560 \mathrm{~K}$ inlet conditions. Also, at atmospheric conditions, Funke et al. showed in a similar experimental setup that the 'investigated combustor module exceeds $99.4 \%$ combustion efficiency for hydrogen contents of $80-100 \%$ in the fuel mixture and shows NOx emissions less than $4 \mathrm{ppm}$ corrected to $15 \mathrm{Vol} . \% \mathrm{O}_{2}$ ' [44]. These values show the potential of micromix combustion to achieve low NOx emissions.

\section{Conclusion}

The results for a hydrogen industrial gas turbine micromix airgate pair with a scaled fuel orifice from $0.3 \mathrm{~mm}$ to $1.0 \mathrm{~mm}$ have been presented in this paper. The key parameters have been varied and two designs were found: an Improved Flame Shape design mimicking the flame shape of the $0.3 \mathrm{~mm}$ Baseline and an Improved Emissions design. According to the results, the scaled Micromix injector can be improved by:

o A narrow and short flame with a high temperature gradient contributing to low residence times.

o A limited recirculation not sucking hot gas upstream to the trailing edge which would lead to NOx formation at the trailing edge.

o High airstream velocity increasing turbulence and decreasing residence time. This leads in general to an increased pressure drop.

o Limiting the concentration of hydroxyl both in value and volume.

o A sufficient penetration depth through, for example, a larger than one Width-to-Height ratio leading to more air flowing around the fuel jet.

The Improved Flame Shape design was able to yield results better than expected due to the separated flames. The emissions were $25 \%$ above the emissions of Baseline $1.0 \mathrm{~mm}$, but the pressure drop was reduced. The pressure drop in combustors is in general around $2 \%$ to $3 \%$. This design offers potential to further reduce the NOx emissions while increasing the pressure drop from below $1 \%$ to a still acceptable level.

The Improved Emissions design compromised pressure loss and performance to reduce the emissions by more than $50 \%$. The hot gas region and the NOx formation volume were reduced by increased mixing and penetration depth as well as reduced residence time. Especially the significance of hydroxyl for the formation of NOx is visible in Fig. 11. Altering the Width-to-Height ratio leads to a higher penetration depth. An increased offset from airgate to fuel injection has a smaller but similar effect. This implies that the penetration depth needs to be increased for a given Momentum Flux Ratio in a scaled micromix setup. A Width-to-Height ratio exceeding the aero counterpart seems beneficial.

The equivalence ratio in this study was kept constant at a value of 0.4. The engine cycle assessment shows potential to further decrease the equivalence ratio by redistributing combustion and cooling air. This might lead to shorter flames and better emissions behavior due to leaner combustion. An analysis of the flame length showed the close coupling of flame length and NOx emissions.

This study helps to understand the challenges and limitations of scaling a micromix injector for ground use. Stationary hydrogen gas turbines have the potential to firm the energy grid by interacting with renewable energy sources. Potentially, fuel of lesser quality is used on ground compared to hydrogen for aviation and the manufacturing cost restrictions on ground favor using a larger fuel orifice. By varying the key design parameters, the negative impact of the increased fuel orifice could be mitigated. Increasing the fuel orifice leads to significant challenges to control NOx and imitating the flame structure of a smaller micromix burner did not yield satisfying results. The strong correlation between pressure loss and emissions was highlighted. Even though the negative impacts were mitigated, all scaled designs led to higher NOx emissions.

Acknowledgements This research complements the research of Cranfield University in the ENABLEH2 project which received funding from the European Union's Horizon 2020 research and innovation programme under grant agreement $\mathrm{N}^{0} 769241$. The author would like to thank Dr. David Abbott and Dr. Xiaoxiao Sun for their support of this project and acknowledges gratefully the cooperation of Cranfield University's Centre for Propulsion Engineering, and Stuttgart University and the German Aerospace Centre's Institute of Combustion Technology, which facilitated this work.

Funding Open Access funding enabled and organized by Projekt DEAL. The Author was funded by the ERASMUS + European Union student exchange program for the time of his placement at Cranfield University (01.10.2020-31.05.2021). This research complements the research of Cranfield University in the ENABLEH2 project which received funding from the European Union's Horizon 2020 research and innovation programme under grant agreement $\mathrm{N}^{\mathrm{o}} 769241$. 
Data availability Using no material but such available in the public domain was a requirement for this research and applies to this paper.

Code availability Computational fluid dynamics: Siemens Star $\mathrm{CCM}+2020.2$ (15.04.008). Other: Microsoft Word and Excel.

\section{Declarations}

Conflicts of interest The author holds currently no other position than student at Stuttgart and Cranfield University. An Non-disclosure agreement for the ENABLEH2 project was signed, but does not apply to this publication.

Open Access This article is licensed under a Creative Commons Attribution 4.0 International License, which permits use, sharing, adaptation, distribution and reproduction in any medium or format, as long as you give appropriate credit to the original author(s) and the source, provide a link to the Creative Commons licence, and indicate if changes were made. The images or other third party material in this article are included in the article's Creative Commons licence, unless indicated otherwise in a credit line to the material. If material is not included in the article's Creative Commons licence and your intended use is not permitted by statutory regulation or exceeds the permitted use, you will need to obtain permission directly from the copyright holder. To view a copy of this licence, visit http://creativecommons.org/licenses/by/4.0/.

\section{References}

1. NASA's Goddard Institute for Space Studies (GISS): Global LandOcean Temperature Index. www.climate.nasa.gov/vital-signs/ global-temperature/ (2021). Accessed 15 Feb 2021

2. Wissenschaftlicher Beirat der Bundesregierung Globale Umweltveränderungen: Welt im Wandel: Sicherheitsrisiko Klimawandel. Springer (2008)

3. Almond, R.E.A., Grootsen, M., Petersen, T.: Living planet report 2020: bending the curve of biodiversity loss. WWF (2020)

4. Füssel, H.-M., Jol, A., Kurnik, B., Hemming, D.: Climate change, impacts and vulnerability in Europe 2012: an indicator-based report. EEA (2012)

5. UNFCCC: The Paris agreement. https://unfccc.int/processand-meetings/the-paris-agreement/the-paris-agreement (2015). Accessed 15 Feb 2021

6. IPCC: Global warming of $1.5^{\circ} \mathrm{C}$. https://www.ipcc.ch/sr15/ (2018). Accessed 15 Feb 2021

7. Schmidt, O., Gambhir, A., Staffell, I., Hawkes, A., Nelson, J., Few, S.: Future cost and performance of water electrolysis: an expert elicitation study. Int. J. Hydrogen Energy (2017). https://doi.org/ 10.1016/j.ijhydene.2017.10.045

8. Adefarati, T., Papy, N.B., Thopil, M., Tazvinga, H.: Non-renewable distributed generation technologies. In: Bansal, R. (ed.) Handbook of distributed generation. https://doi.org/10.1007/978-3-31951343-0_2 (2017)

9. Glassman, I., Yetter, R.A., Glumac, N.G.: Combustion, 5th edn. Elsevier (2014)

10. Lefebvre, A.H., Ballal, D.R.: Gas turbine combustion. CRC Press (2010)

11. Wisniewski, K.J., Handelsman, S.: Expanding fuel flexibility capability in GE's aeroderivative engines. Proc. ASME Turbo. Expo. (2010). https://doi.org/10.1115/GT2010-23546

12. Poloczek, V., Hermsmeyer, H.: Modern gas turbines with high fuel flexibility. POWER-GEN Asia (2008)
13. Japan claims world first: DLN gas turbine combustors verified on $100 \%$ hydrogen. Modern Power Systems. https://www.moder npowersystems.com/features/featurejapan-claims-world-firstdln-gas-turbine-combustors-verified-on-100-hydrogen-8185077/ (2020). Accessed 3 Mar 2021

14. Sethi, V.: ENABLing cryogEnic Hydrogen based $\mathrm{CO} 2$ free air transport (ENABLEH2). https://www.enableh2.eu (2018). Accessed 15 Feb 2021

15. Ben Abdallah, R., Sethi, V., Gauthier, P., Rolt, A.M., Abbott, D.: A detailed analytical study of hydrogen reaction in a novel micromix combustion system. Proc. ASME Turbo. Expo. (2018). https://doi.org/10.1115/GT2018-76586

16. Babazzi, G., Gauthier, P., Agarwal, P., McClure, J., Sethi, V.: NOX emissions predictions for a hydrogen micromix combustion system. Proc. ASME Turbo. Expo. (2019). https://doi.org/10.1115/ GT2019-90532

17. Sun, X., Agarwal, P., Carbonara, F., Abbott, D., Gauthier, P. Sethi, B.: Numerical investigation into the impact of injector geometrical design parameters on hydrogen micromix combustion characteristics. Proc. ASME Turbo. Expo. (2020). https://doi.org/ 10.1115/GT2020-16084

18. López-Juárez, M., Sun, X., Sethi, B., Gauthier, P., Abbott, D.: Characterising hydrogen micromix flames: combustion model calibration and evaluation. Proc. ASME Turbo. Expo. (2020). https://doi.org/10.1115/GT2020-14893

19. Zghal, M., Sun, X., Gauthier, P., Sethi, V.: Comparison of tabulated and complex chemistry turbulent-chemistry interaction models with high fidelity large eddy simulations on hydrogen flames. Proc. ASME Turbo Expo. (2020). https://doi.org/10.1115/ GT2020-16070

20. Agarwal, P., Sun, X., Gauthier, P., Sethi, V.: Injector design space exploration for an ultra-low NOx hydrogen micromix combustion system. Proc ASME Turbo. Expo. (2019). https://doi.org/10.1115/ GT2019-90833

21. Khandelwal, B., Li, Y., Murthy, P., Sethi, V., Singh, R.: Implication of different fuel injector configurations for hydrogen fuelled micromix combustors. Proc ASME Turbo Expo (2011). https:// doi.org/10.1115/GT2011-46845

22. McClure, J., Abbott, D., Agarwal, P., Sun, X., Babazzi, G., Sethi, V., Gauthier, P.: Comparison of hydrogen micromix flame transfer functions determined using RANS and LES. Pro. ASME Turbo. Expo. (2019). https://doi.org/10.1115/GT2019-90538

23. Abbott, D., Giannotta, A., Sun, X., Gauthier, P., Sethi, V.: Thermoacoustic behaviour of a hydrogen micromix aviation gas turbine under typical flight conditions. Accepted for publication in the Proceedings of ASME Turbo Expo 2021, Turbomachinery Technical Conference and Exposition, GT2021, June 7-11, 2021 , Virtual, Online. (2021)

24. Sun, X., Abbott, D., Singh, A., Gauthier, P., Sethi, B.: Numerical investigation of potential cause of instabilities in a hydrogen micromix injector array. Accepted for publication in the Proceedings of ASME Turbo Expo 2021, Turbomachinery Technical Conference and Exposition, GT2021, June 7-11, 2021, Virtual, Online. (2021)

25. Lechner, C., Seume, J.: Stationäre gasturbinen. Springer (2010)

26. Boyce, M.P.: Gas turbine engineering handbook. Elsevier (2012)

27. Drell, I.L., Belles, F.E.: NACA Research Memorandum: Survey of hydrogen combustion properties. (1957)

28. Global, E.T.N.: Hydrogen gas turbines - the path towards a zerocarbon gas turbine. ETN Global (2020)

29. Gobbato, P., Masi, M., Toffolo, A., Lazzaretto, A.: Numerical simulation of a hydrogen fuelled gas turbine combustor. Int. J. Hydrogen Energy (2011). https://doi.org/10.1016/j.ijhydene.2011. 01.045 
30. Dahl, G., Suttrop, F.: Engine control and low-nox combustion for hydrogen fuelled aircraft gas turbines. Int J Hydrogen Energy (1998). https://doi.org/10.1016/s0360-3199(97)00115-8

31. Funke, H.H.-W., Beckmann, N., Keinz, J., Horikawa, A.: 30 years of dry low NOx micromix combustor research for hydrogen-rich fuels: an overview of past and present activities. J. Eng. Gas. Turbines Power (2021). https://doi.org/10.1115/1.4049764

32. Marek, C., Smith, T., Kundu, K.: Low emission hydrogen combustors for gas turbines using lean direct injection. 41st AIAA/ ASME/SAE/ASEE joint propulsion conference and exhibit (2005). https://doi.org/10.2514/6.2005-3776.

33. York, W.D., Ziminsky, W.S., Yilmaz, E.: Development and testing of a low NOx hydrogen combustion system for heavy-duty gas turbines. J. Eng. Gas. Turbines Power (2013). https://doi.org/10. $1115 / 1.4007733$

34. Asai, T., Dodo, S., Koizumi, H., Takahashi, H., Yoshida, S., Inoue, H.: Effects of multiple-injection-burner configurations on combustion characteristics for dry low-NOx combustion of hydrogenrich fuels. Proc. ASME Turbo Expo. (2011). https://doi.org/10. 1115/GT2011-45295

35. Ayed, A.H., Kusterer, K., Funke, H.H.W., Keinz, J., Bohn, D.: CFD based exploration of the dry-low-NOx hydrogen micromix combustion technology at increased energy densities. Prop. Power Res. (2017). https://doi.org/10.1016/j.jppr.2017.01.005

36. Siemens Energy: SGT-A35 (Industrial RB211) aeroderivative gas turbine. https://www.siemens-energy.com/global/en/offer ings/power-generation/gas-turbines/sgt-a30-a35-rb.html (2021). Accessed 19 Feb 2021

37. Ansys Inc.: ANSYS Fluent Theory Guide. Ansys Inc., Canonsburg. https://support.ansys.com/AnsysCustomerPortal/en_us/ Downloads/Current+Release (2014). Accessed 20 Mar 2021

38. Naik, C., Puduppakkam, K., Meeks, E.: An improved core reaction mechanism for saturated $\mathrm{C} 0-\mathrm{C} 4$ fuels. J. Eng. Gas Turbines Power (2012). https://doi.org/10.1115/1.4004388
39. Farmer, R., de Biasi, B., Isles, J., Jaeger, H., Asquino, M., Cornett, M., Janson, J., de Biasi, V.: Gas turbine world 2014 performance specs. Pequot Publishing (2014)

40. Funke, H.H.W., Beckmann, N., Keinz, J., Abanteriba, S.: Comparison of numerical combustion models for hydrogen and hydrogen-rich syngas applied for dry-low-nox-micromix-combustion. J. Eng. Gas Turbines Power (2018). https://doi.org/10.1115/1.40388 82

41. Konnov, A.: Remaining uncertainties in the kinetic mechanism of hydrogen combustion. Combust. Flame (2008). https://doi.org/10. 1016/j.combustflame.2007.10.024

42. Kéromnès, A., Metcalfe, W., Heufer, K., Donohoe, N., Das, A., Sung, C., Herzler, J., Naumann, C., Griebel, P., Mathieu, O., Krejci, M., Petersen, E., Pitz, W., Curran, H.: An experimental and detailed chemical kinetic modeling study of hydrogen and syngas mixture oxidation at elevated pressures. Combust. Flame (2013). https://doi.org/10.1016/j.combustflame.2013.01.001

43. Saxena, P., Williams, F.: Testing a small detailed chemical-kinetic mechanism for the combustion of hydrogen and carbon monoxide. Combust. Flame (2006). https://doi.org/10.1016/j.combustflame. 2005.10.004

44. Funke, H.H.W., Beckmann, N., Abanteriba, S.: Development and testing of a fuelflex dry-low-NOx micromix combustor for industrial gas turbine applications with variable hydrogen methane mixtures. Proc. ASME Turbo Expo. (2019). https://doi.org/10. 1115/GT2019-90095

Publisher's Note Springer Nature remains neutral with regard to jurisdictional claims in published maps and institutional affiliations. 